\title{
Infestation of Ixodidae Ticks in Cattle: Prevalence and Associated Risk Factors in Ambo District, Western Ethiopia
}

\author{
Addis Kassahun Gebremeskel*, Berhanu Mekibib and Bekele Dabassa
}

Faculty of Veterinary Medicine, College of Natural and Computational Sciences, Hawassa University, Hawassa, Ethiopia, P. O. Box 05

\section{KEYWORDS:}

Ambo district;

Cattle;

Ectoparasites;

Prevalence;

Risk factors;

Ticks

\begin{abstract}
In Ethiopia, ticks cause serious economic loss particularly in ruminants. A cross sectional study was conducted in Ambo district, Western Ethiopia from October, 2018 to June, 2019 with the objectives of determining the prevalence, identifying the associated risk factors and the tick species of cattle in the area. From five purposively selected kebeles (the smallest administrative unit of Ethiopia) of the district, a total of 384 cattle were selected by systematic random sampling method. Adult Ixodid ticks were collected from different body parts of infested cattle, preserved in $10 \%$ formalin and transported to Ambo University Veterinary Parasitology Laboratory for stereomicroscopic identification to species level. Among 384 cattle examined, 201 (52.34\%) cattle were infested with one or two tick species. Higher prevalence of tick infestation was recorded in Degele Gatira kebele (53.25\%), followed by Abebe Doyo (50.65\%), Gosu Kora (50.65\%), Kisose Liban $(50.65 \%)$ and Senkele Faris $(56.59 \%)$. The study investigated three genera of Ixodid ticks namely Rhipicephalus (41.7\%), Boophilus (0.8\%) and Amblyomma (2.60\%). Mixed infestations were common including Rh. Boophilus and Amblyomma 24(6.25\%) and Rh. Boophilus and Rhipicephalus 4(1.04\%). The study identified four species of ticks; namely Rh. (Bo.) decoloratus 109 (28.40\%), Rhipicephalus (Boophilus) annulatus 43(11.20\%), Amblyomma vareigatum 3(0.80\%) and Rhipicephalus evertsi evertsi 11(2.90\%). The difference in tick infestation was found to be statistically insignificant $(\mathrm{P}>0.05)$ between different age groups and kebeles but statistically significant $(\mathrm{P}<0.05)$ among sex groups, breeds and different body condition scores $(\mathrm{P}<0.05)$. In conclusion, this study indicated high prevalence of tick infestation and identified most important ticks that can transmit various livestock diseases. Proper tick eradication campaign should be conducted to reduce the tick burden in the study area, and concomitantly reduce tick-borne diseases and associated economic losses.
\end{abstract}

\section{INTRODUCTION}

Ethiopia has an enormous and diverse livestock population that plays an important role in the economy and livelihoods of farmers and pastoralists (Akande et al., 2010). The country

\footnotetext{
*Corresponding author:

Email: addisk2013@gmail.com, +251909164446
}

has 65 million cattle, 40 million sheep, 51 million goats, 8 million camels and 49 million chickens. From the total cattle population, $97.8 \%, 1.9 \%$ and $0.3 \%$ cattle are indigenous, hybrid and exotic, respectively (CSA, 2020). Despite the large animal population, their

\section{https://dx.doi.org/10.4314/eajbcs.v3i1.3S}


productivity is low due to poor nutrition, reproduction insufficiency, management constraints and prevailing livestock diseases (Bekele et al., 2010).

Parasitic diseases are among the major problems of domestic animals causing serious economic loss (Shiferaw, 2018). Ectoparasites are organisms which inhibits the skin or outgrowth of the skin of the host for various periods (Hopla et al., 1994). In Ethiopia, Ectoparasites in ruminant causes serious economic losses to small holder farmers, the tanning industry and the country as a whole through mortality, decreased production, downgrading and rejection of skin and hide (Peter, 2005). Ectoparasites can live permanently on their host, or they may occupy the host's nest and immediate environment, and visit the body of the host periodically (Gross et al., 2005). In either case, there is a close dependency on the host for various life sustaining resources (Gonzalez et al., 2004). From the Ectoparasites, ticks are ranked as the most economically important arthropods in tropics including subSaharan Africa (Abdela, 2016).

Ticks have adverse effect on livestock in several ways and parasitize a wide range of vertebrate hosts and transmit a wide variety of pathogenic agents than any other group of arthropods (Oliver, 1989; Belew and Mekonnen, 2011). Ticks transmit protozoa, bacterial, rickettsial and viral diseases. Moreover, Ticks down grade hide and skins quality and reduce milk and wool production, reduce productivity and increase susceptibility to the other diseases (de Castro, 1997). Ticks can predispose animals to secondary attacks from other parasites such as screw worm flies and infection by pathogens such as Dermatophilos congolensis, the causative agent of streptothricosis (Desta, 2010). There are various cattle tick-borne diseases in Ethiopia such as anaplasmosis, babesiosis, theileriosis (Mekonnen et al., 1992) and streptothricosis (Surafel and Amsalu, 2019).
In spite of the aforementioned prevailing situation and the presence of a number of problems due to ticks in Ethiopia, there is paucity of well-documented information on the prevalence of existing species and associated risk factors of ticks in cattle in the study area. Therefore, this study was designed with the objectives of estimating the prevalence of tick infestation, identifying existing species of ticks and assessing risk factors associated with the occurrence of tick in cattle in Ambo district, western Ethiopia.

\section{MATERIALS AND METHODS}

\section{Description of the study area}

The study was conducted in five kebeles (The smallest administrative unit of Ethiopia) of Ambo district namely Degele Gatra, Abebe Doyo, Gosu Kora, Kisose Liben and Senkele Faris from October, 2018 to June, 2019. Ambo district has a total of 35 kebeles. The area is located at latitude and longitude of $8^{\circ} 59^{\prime} \mathrm{N}, 37^{\circ}$ 51 'E, respectively and an elevation of $2101 \mathrm{~m}$ above sea level. Ambo has livestock populations of 145, 371 cattle, 50,152 sheep, 27, 026 goats, 9, 088 horses, 2, 914 donkeys and 256 mules. The area is characterized by bimodal rainfall with mean annual rainfall of $1129 \mathrm{~mm}$ per year and annual temperature ranging from 10 to $28^{\circ} \mathrm{C}$ (CSA, 2007; Firaol et al., 2014) .

\section{Study Design and Study population}

A cross sectional study was conducted on a total of 384 cattle randomly selected from the population. The study populations were includes both local and exotic breeds of cattle with different ages, sex and body condition cores. Out of the 35 kebeles found in the district, five kebeles were selected purposively for their accessibility and large cattle population. The age of the cattle was estimated based on the description given by Nicholson and Butterworth (1996), and then categorized as young ( $\leq$ year), 
adult (1-3 years) and old ( $\geq 3$ years). Similarly, based on their body condition scores, the cattle were classified as good, medium and poor.

\section{Sample Size Determination and Sampling Method}

The minimum sample size required for this study was determined according to the formula given by Thrusfield and Brown (2018). Accordingly, 95\% confidence interval, 5\% precision and $50 \%$ expected prevalence was used as there was no previous study conducted in the area.

$$
\begin{aligned}
\mathrm{N} & =\frac{Z^{2} * P(1-P)}{d^{2}} \\
& =\frac{1.96^{2} * 0.5(1-0.5)}{0.05^{2}}
\end{aligned}
$$

Where, $\mathrm{N}=$ required sample size, $\mathrm{Z}=$ confidence interval $(95 \%)$, Pexp= expected prevalence and $\mathrm{d}=$ desired absolute precision. Therefore, the computed sample size was 384 .

\section{Collection \& laboratory examination of ticks}

Animals' body was visually examined for tick infestation and adult ticks were collected by using universal bottle containing $10 \%$ formalin.

\begin{tabular}{|c|c|c|c|c|c|}
\hline \multicolumn{2}{|c|}{ Risk factors } & \multirow{2}{*}{$\begin{array}{l}\text { Number examined } \\
66\end{array}$} & \multirow{2}{*}{$\begin{array}{l}\text { Prevalence n }(\%) \\
26(39.40)\end{array}$} & \multirow{2}{*}{$\frac{\chi^{2}}{1.3}$} & \multirow{2}{*}{$\frac{\mathrm{p} \text {-value }}{0.515}$} \\
\hline Age & Young (1 year) & & & & \\
\hline & Adult (1-3 year) & 195 & $107(54.90)$ & & \\
\hline & Old (>3 year) & 123 & $63(51.22)$ & & \\
\hline \multirow[t]{2}{*}{ Sex } & Male & 190 & $83(43.70)$ & 11.3 & 0.001 \\
\hline & Female & 194 & $118(60.62)$ & & \\
\hline \multirow[t]{3}{*}{ Breed } & Local & 298 & $144(48.32)$ & & \\
\hline & $\mathrm{HF}$ & 86 & $57(66.30)$ & 8.6 & 0.003 \\
\hline & Good & 198 & $79(39.90)$ & & \\
\hline \multirow[t]{4}{*}{ BCS } & Medium & 117 & $60(51.30)$ & & \\
\hline & Poor & 69 & $62(89.60)$ & 51.2 & 0.000 \\
\hline & DegeleGatra & 77 & $41(53.25)$ & & \\
\hline & Abebe Doyo & 77 & $39(50.65)$ & & \\
\hline \multirow[t]{3}{*}{ Kebele } & GosuKora & 77 & $39(50.65)$ & 0.838 & 0.933 \\
\hline & KisoseLiben & 77 & $39(50.65)$ & & \\
\hline & SenkeleFaris & 76 & $43(56.60)$ & & \\
\hline
\end{tabular}

Table 1: Relation between tick infestation and risk
Each sample was correctly labeled (with age, sex, breed, Body condition and kebeles) and transported to Ambo University veterinary Parasitology Laboratory for identification to species level by using stereomicroscopic. Ticks identification was conducted following previous protocol described by Wall and Shearer (2001).

\section{Data analysis}

Data collected from the field and the laboratory were entered in to Microsoft Excel spread sheet and coded, and then analyzed using SPSS version 20. Descriptive statistics were used to know the prevalence of tick infestation, and association between the tick infestations and host risk factors (sex, age, breed, body condition score and kebeles) was assessed by Pearson Chi square test.

\section{RESULTS}

Out of 384 cattle examined, 201 (52.34\%) were found infested with one or more ticks' species. There were statistically significant $(\mathrm{P}<0.05)$ association between tick infestation and sex, breeds and body condition scores whereas it was statistically insignificant $(\mathrm{P}>0.05)$ with age groups and kebeles (Table 1). 
The study investigated three genera of adult Ixodid ticks; namely Rhipicephalus (41.7\%), Boophilus (0.8\%), Amblyomma (2.60\%). Mixed infestations were common by Rhipicephalus
(Boophilus) and Amblyomma 24(6.25\%) and Rhipicephalus (Boophilus) and Rhipicephalus $4(1.04 \%)$ (Table 2).

Table 2: Distribution of tick genera in Ambo district, western Ethiopia from October 2018 to June 2019

\begin{tabular}{lc}
\hline Genus of ticks & Prevalence (\%) \\
\hline Amblyomma & $3(0.80)$ \\
Rhipicephalus (Boophilus) & $160(41.70)$ \\
Rhipicephalus & $10(2.60)$ \\
Amblyoma \& Rhihipicephalus (Boophilus) & $24(6.25)$ \\
Rhipicephalus (Boophilus) \& Rhipicephalus & $4(1.04)$ \\
Total & $\mathbf{2 0 1}(\mathbf{5 2 . 4})$ \\
Species & \\
Rh. (B.) annulatus & $43(11.20)$ \\
Rh. (B.) decoloratus & $109(28.40)$ \\
A. variegatum & $3(0.80)$ \\
Rh. e. evertsi & $11(2.90)$ \\
Rh. (B.) annulatus \& A. variegatum & $3(0.80)$ \\
Rh. (B.) annulatus \& Rh.(B.) decolratus & $6(1.60)$ \\
Rh. (B.) decoloratus \& Rh. e. evertsi & $2(0.52)$ \\
..Rh. (B.) decoloratus \& A. variegatum & $21(5.50)$ \\
Rh. (B.) annulatus \& Rh.e. evertsi. & $3(0.80)$ \\
\hline
\end{tabular}

\section{DISCUSSION}

The overall prevalence of tick infestation $(52.34 \%)$ recorded in the current study is comparable with previous report made by Tadele et al. (2018) (51.30\%). However, it was far lower than the finding of Dabasa et al. (2017) (98.20\%) and higher than the report of Surafel and Amsalu (2019) 186(33.21\%). According to Pegram et al. (1981), tick activities and prevalence in a given area are influenced by rainfall, temperature, altitude and atmospheric relative humidity and management system including the use of accaricide and other preventive measures, agro-climatic condition and other epidemiological factors.

Cross breed cattle were highly affected by tick infestation compared with local breed cattle. This finding was in line with the result of Belay and Enyew (2016). However, it disagrees with the report of Surafel and Amsalu (2019). The higher prevalence of tick infestation in cross and pure exotic breed animals might be attributed to preimmunity against ectoparasites, which often established through contacts with the parasites at the early stage of their life (Ahmed et al., 2012).

The proportion of infestation was higher in adult and old animals as compared to young animals, which was most likely due to outdoor management and long distant mobilization of adult and old animals in search of feed and water as the result the chance of exposure to tick could be higher than that of younger animals (Sutherst and Maywald, 1983). In the current study, female cattle were more infested by tick $(60.82 \%)$ than male cattle $(54.90 \%)$. This finding was in line with the report of Shichibi et 
al. (2017) in Masha district. This could be partly explained by the high chance of physiological stress (pregnancy or lactation) which create favorable conditions to tick infestation and other external parasite infestations (Sutherst and Maywald, 1983).

Having poor body condition resulted in higher prevalence of tick infestation compared to medium and good body conditioned animals. This result was comparable with previous reports such as Fanos et al. (2012) who conducted similar study in and around Mizan Teferi, Southwestern Ethiopia. However, this result is not in line with a study conducted in Gozamin Woreda, East Gojjam (Tadele et al., 2018). Poor body conditioned animals had reduced resistance to tick infestation, lack of enough body potential to build resistance and they exposed to any kind of diseases when grazing on the field (Manan et al., 2007). On the other possible scenario, the poor body condition observed in those cattle with tick infestation could be due to the effect of the parasite on the energy balance of the animal.

In this study $R h$. (B.) decolaratus was found to be the most abundant tick species $(28.40 \%)$. This result was in line with Wasihun and Doda (2013) who reported the prevalence of $R h$. (B.) decoloratus as $30.63 \%$ conducted in Humbo district. According to Shiferaw (2005), Rh. (B.) decolaratus had highest frequency during dry seasons (January, February and early March). In contrast to Amante et al. (2014), this finding was lower. The variations could be due to factors such as geography, altitude and seasons when ticks were collected. Furthermore, $R h$. e.evertsi was the third abundant tick species consisted $6.72 \%$ of the total adult tick collected. This result was slightly in line with the report of Abebe et al. (2010) conducted in Somali region, Ethiopia.

\section{CONCLUSION}

Tick infestation is the common problem in the study area that occurs on every other animal. In this study, Rhipicephalus (Boophilus) decoloratus are the leading genus of ticks affecting mainly exotic and cross breed, female cattle with poor body condition of adult to old age. Although, the prevalence of ticks was high in the study area, proper policies and strategies are not yet in place to control ticks and other external parasites. Therefore, sustainable tick control program should be introduced in order minimize the prevalence to the lowest level so that tick born diseases and other tick associated problems can be prevented.

\section{Acknowledgment}

The authors would like to thank Hawassa University and Ambo University for supporting this study.

\section{References}

Abdela N. 2016. Important cattle ticks and tick born haemoparasitic disease in Ethiopia: a review. Acta Parasitol Glob 7(1): 12-20

Abebe R., Fantahun T., Abera M. and Bekele J. 2010. Survey of ticks (Acari: Ixodidae) infesting cattle in two districts of Somali Regional State, Ethiopia. Vet. World 3(12): 539-543.

Ahmed S., Numan M., Manzoor A.W. and Ali F.A. 2012. Investigations into Ixodidae ticks in cattle in Lahore, Pakistan. Vet Ital. 48: 185-191.

Akande F., Takeet I. and Makanju O. 2010. Haemoparasites of cattle in Abeokuta, south west Nigeria. Sci. World J. 5: 19-21.

Amante M., Alelgn Z. and Hirpa E. 2014. Prevalence of Ixodid Ticks on Cattle in and Around Diga Town, West Ethiopia. Eur. J. Biol. Sci. 6(1): 25-32.

Bekele J., Asmare K., Abebe G., Ayelet G. and Gelaye E. 2010. Evaluation of Deltamethrin applications in the control of tsetse and trypanosomosis in the southern rift valley areas of Ethiopia. Vet. Parasitol. 168: 177-184.

Belay W. and Enyew M. 2016. Identification and Prevalence of Hard Tick in and Around Sude Woreda, Arsi Zone, Ethiopia. Journal of Health, Medicine and Nursing 28:13-19.

Belew T. and Mekonnen A. 2011. Distribution of Ixodid Ticks on Cattle in and Around Holeta Town, Ethiopia. Journal of Global Veterinaria 6: 527-531.

CSA, 2007. July. Agricultural Sample Survey 200607." Volume I, Addis Ababa 
CSA. 2020. Agricultural sample survey 2019/20 (2012 E.C) volume II report on livestock and livestock characteristics (private peasant holdings). Central statistical agency (CSA)): Addis Ababa, Ethiopia

Dabasa, G., Zewdei, W., Shanko, T., Jilo, K., Gurmesa, G. and Lolo, G., 2017. Composition, prevalence and abundance of Ixodid cattle ticks at Ethio-Kenyan Border, Dillo district of Borana Zone, Southern Ethiopia. J. Vet. Med. Anim. Health 9(8): 204-212.

de Castro J.J. 1997. Sustainable tick and tickborne disease control in livestock improvement in developing countries. Vet. Parasitol. 71(2-3): 77-97.

Desta A.H. 2016. One health: an integrated approach for disease prevention and control in pastoral areas of Ethiopia. Journal of Health, Medicine and Nursing 22: $45-50$.

Fanos T., Gezali A., Sisay G., Bersissa K. and Tariku J. 2012. Identification of tick species and their preferred site on cattle's body in and around Mizan Teferi, Southwestern Ethiopia. J. Vet. Med. Anim. Health 4(1): 1-5.

Firaol T., Dagmawit A., Askale G., Solomon S., Morka D. and Waktole T. 2014. Prevalence of ectoparasite infestation in chicken in and around Ambo Town, Ethiopia. . J. Veterinar. Sci. Technol. 5(4): 189. doi:10.4172/2157-7579.1000189

Gonzalez A., Castro D. and Gonzalez S. 2004. Ectoparasitic species from Canis familiaris (Linne) in Buenos Aires province, Argentina. Vet. Parasitol. 120: 123-129.

Hopla C., Dureden L. and Keirans J. 1994. Ectoparasites and Classification. Revolution of Science and Technology 13: 985-1017.

Mekonnen S., Gebre S., Hussein I. and Regassa A. 1992. Ticks, tick-borne diseases and their control in Western Ethiopia. Int. J. Trop. Insect. Sci. 13: 661664.

Nicholson M. and Butterworth T. 1996. A guide to body condition score in zebu cattle international livestock center for Africa. Addis Ababa, Ethiopia.
Oliver Jr, J.H., 1989. Biology and systematics of ticks (Acari: Ixodida). Annual review of Ecology and Systematics, 20(1), pp. 397-430.

Pegram G., Hoogsstraal H. and Wassef P. 1981. Ticks Argasidae, Ixodidae of Ethiopia; Distribution, ecology and host relationship of species Infecting livestock. Bull. Entomol. Res. 71: 339-359.

Peter R., Van Den Bossche P., Penzhorn L. and Sharp B. 2005. Tick, fly and mosquito control Lessons from the past, solutions for the future. Vet. Parasitol. 132(3-4): 205-215.

Shichibi T.H., Edere M.S. and Mekitet T.F. 2017. Bovine Ixodid ticks: prevalence, distribution and associated risk factors in Saylem, Gesha and Masha districts, Southern Ethiopia. Adv. Biol. Res. 11(5): 265-270.

Shiferaw S. 2018. An overview of ectoparasites on domestic animals in Ethiopia. J. Veter. Sci. Med. 6(1): 1 - 5 .

Surafel A. and Amsalu Y. 2019. Prevalence of cattle tick infestation in and around Haramaya district, Eastern Ethiopia. Int. J. Vet. Med. Animal Health 10(5): 8488 .

Sutherst R, Kerry J, Maywald G. 1983. Effect of season and nutrition on the resistance of cattle to tick Boophilus microplus. Aus J Agri Res. 34:329-39

Tadele L., Biniyam M. and Mulat A. 2018. A cross sectional study on the prevalence and identification of major ixodid tick parasites of cattle in Gozamin Woreda, East Gojjam, and Ethiopia. J. Anim. Res. 8(4): 555 - 560 .

Thrusfield M. and Brown H. 2018. Survey. In: Thrusfield M. (Ed.), Veterinary Epidemiology fourth ed. Hoboken, NJ: Wiley. Pp 275-277.

Wall R. and Shearer D. 2001. Veterinary Ectoparasites: Biology, Pathology and Control. Blackwell's Science Ltd.

Wasihun P. and Doda D. 2013. Study on prevalence and identification of ticks in Humbo district, Southern Nations, Nationalities, and People's Region (SNNPR), Ethiopia. J. Vet. Med. Anim. Health 5(3): 73-80. 